\title{
Research Paper: Studying the Environmental Health Condition of the Cities in the Kermanshah Province Affected by 2017 Earthquake
}

\author{
Amir Karami ${ }^{1}$, Abdollah Dargahi ${ }^{2}$, Mehrdad Farrokhi ${ }^{3}$, Mohsen Poorsadeghian ${ }^{4,3}$, Reyhaneh Ivanbagha $^{5}$, Parvin Mostafaei ${ }^{1}$, Leila Tabandeh $^{1^{*}}$ (1)
}

1. Department of Environmental Health Engineering, Faculty of Public Health, Kermanshah University of Medical Sciences, Kermanshah, Iran.

2. Student Research Committee, Hamadan University of Medical Sciences, Hamadan, Iran.

3. Health in Emergency and Disaster Research Center, University of Social Welfare and Rehabilitation Sciences, Tehran, Iran.

4. Department of Ergonomics, Pediatric Neurorehabilitation Research Center, University of Social Welfare and Rehabilitation Sciences, Tehran, Iran.

5. Department of Midwifery, Faculty of Nursing and Midwifery, Khalkhal University of Medical Sciences, Khalkhal, Iran.

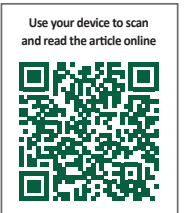

Citation: Karami A, Dargahi A, Farrokhi M, Poorsadeghian M, Ivanbagha R, Mostafaei P, et al. Studying the Environmental Health Condition of the Cities in the Kermanshah Province Affected by 2017 Earthquake. Health in Emergencies and Disasters Quarterly. 2018; 4(1):29-36. http://dx.doi.org/10.32598/hdq.4.1.29

\section{(i) (8)}

Funding: See Page 35

Article info:

Received: 17 May 2018

Accepted: 02 Sep 2018

Available Online: 01 Oct 2018

\section{Keywords:}

Earthquake, Environmental health, Risk, Natural disaster, Food safety

\section{ABSTRACT}

Background: Natural disasters are out of human control, often leading to loss of life and property, and particularly affecting public health. Natural disasters influence human lives in different ways. They may have severe, obvious, or hidden consequences. Therefore, the present study aimed at examining the environmental health condition of the cities affected by 2017 earthquake in Kermanshah Province.

Materials and Methods: This was a cross-sectional study. The environmental health experts gathered and analyzed the study data regarding the environment health condition of public places, food safety, solid waste management, types and number of water supplies, number of healthcare facilities and local health centers, etc.

Results: According to the results, the lowest and highest number of damaged villages in Kermanshah Province were located in Sarpol-e Zahab (205 villages) and Qasr-e Shirin (29 villages), respectively. In addition, Eslamabad-e Gharb and Salas-e Babajani had the highest and lowest urban and rural populations, respectively. A total of 138564 people were affected by the earthquake. The improved water sources in the affected areas included 51 low-risk water sources, 171 moderate-risk water sources, 2 high-risk water sources, and 0 very highrisk water sources. In addition, $5059 \mathrm{~m}^{3}$ water was chlorinated by the environmental health experts and 1805 households were under the coverage of methoxymethyl chloride. Moreover, public healthcare centers (1059 intact and 605 damaged), 4564 food safety centers (3204 intact and 1360 damaged), and 20 solid waste management centers (16 intact and 4 damaged) were available in the area after the earthquake.

Conclusion: Overall, the results indicate that the environmental health activities in the areas affected by the earthquake were adequate in terms of providing healthy drinking water, garbage and wastewater management, distribution of healthy foods, and so on. Thus it can be used as a good model to response the needs of the survivors from the future natural disasters and crises.

\section{* Corresponding Author:}

Leila Tabandeh, MSc.

Address: Department of Environmental Health Engineering, Faculty of Public Health, Kermanshah University of Medical Sciences, Kermanshah, Iran E-mail: tabandehleila179@gmail.com 


\section{Introduction}

nexpected disasters are defined as situa-

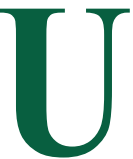
tions in which the society loses its control to run normal functions. As a result of a sudden natural or unnatural disaster with its destructive effects, the society is unable to fulfill its healthcare duties [1]. Today, loss of life and property as a result of natural or unnatural disasters has an undeniable impact on human being's health and lifestyle. The destructive effects of disasters can impair the societies' ability in response to the basic demands and may lead to widespread deaths and injuries $[2,3]$. Natural disaster is a severe geographical collapse or a high-emergency situation that can result in death, injury, illness, and property damage, and cannot be effectively controlled by the available resources and methods, therefore requires foreign aid. Natural disorders are, in fact, acute and sudden phenomena with deep effects on the society [4]. Natural disasters can lead to widespread death and destruction depending on their nature and severity.

For example, 2004 Indian Ocean tsunami or the natural disasters in the United States in 1999 led to large buildup of waste about 5 to 15 times the waste normally produced in those areas [5]. According to a report by the UNISDR (The United Nations International Strategy for Disaster Reduction), from 2000 to 2012, natural disasters accounted for 1.2 million people death and \$ 1.7 billion damage around the world [6, 7]. Recent studies indicate that Asia and Australia are particularly vulnerable to natural disasters, and often face with a wide range of natural disasters, including floods, earthquakes, storms etc. $[8,9]$. Iran is among the 10 most-prone countries to natural disasters. In fact, of 43 types of disasters known around the world, 34 has already occurred in Iran [4, 5], and $90 \%$ of the Iran population are vulnerable to natural disasters, such as earthquakes and floods [10].

Earthquake is the most frequent and destructive natural disaster in Iran. Otherwise speaking, in the past 90 years, earthquakes in Iran have led to death of more than 180000 people, with the Bam earthquake being a prominent example in which 30000 people were killed and 10000 more were injured [11]. Iran's seismic hazard zoning map shows that urban and rural areas of Iran are largely located in the high relative risk zones [10]. In addition, most of Iranian cities, such as Tehran, Tabriz, Qazvin, Zanjan, Hamadan, and Kermanshah have experienced earthquakes and the resulting destructions. According to the earthquake recurrence interval formula, these cities are still vulnerable to earthquakes [10].
However, the required laws and capacity for providing healthcare services for natural disaster victims have made available [12-14] in Iran in recent years. Thus, the environmental health unit as one of the main organizations involved in the crisis management during natural disasters is obliged to take specific measures during emergencies, including restoration, maintenance, and improvement of the health conditions in the damaged areas. It can strongly be argued that environmental health activities, such as water supply, waste and wastewater management, food safety etc. Play a key role in times of natural disasters, and if properly implemented, can prevent epidemics and facilitate the return of normal conditions. Therefore, the present study aimed to examine the environmental health condition of the cities affected by 2017 earthquake in Kermanshah Province.

\section{Materials and Methods}

This is a cross-sectional study conducted in November 2017. The data on the environmental health condition were gathered using special forms designed by the environmental experts in Kermanshah Province. These forms covered the health condition of public places, food safety, solid waste management, types and number of water supplies, number of healthcare facilities, local health centers and so on. Immediately after entering environmental health groups of Kermanshah in the damaged areas, a quick analysis was conducted on the environmental health condition, the extent of damage, and the urgent demands. Then, the collected data were statistically analyzed and presented in data sheets. This provided an appropriate ground for continuing the process of recovery in the damaged areas and also the health management of the population under study.

Kermanshah earthquake affected a wide geographical area and a large population. It had an immense destructive impact on both human lives and properties. The epicenter of Kermanshah earthquake was near Ezgeleh, a city in Kermanshah Province (Figure 1). The earthquake occurred on November 12, 2017 at 21:48 local time, at 45.9 degrees longitude and 34.84 degrees latitude, at the depth of $11 \mathrm{~km}$. In addition, the earthquake was followed by two other quakes with magnitudes of 4.6 and 4 in Richter scale, respectively. The most affected cities in Kermanshah Province were as follows: Sarpol-e Zahab, Salas-e Babajani, Qasr-e Shirin, Dalahoo, and Eslamabad-e Gharb. Therefore, the study participants were selected using a census method from these 6 cities. 


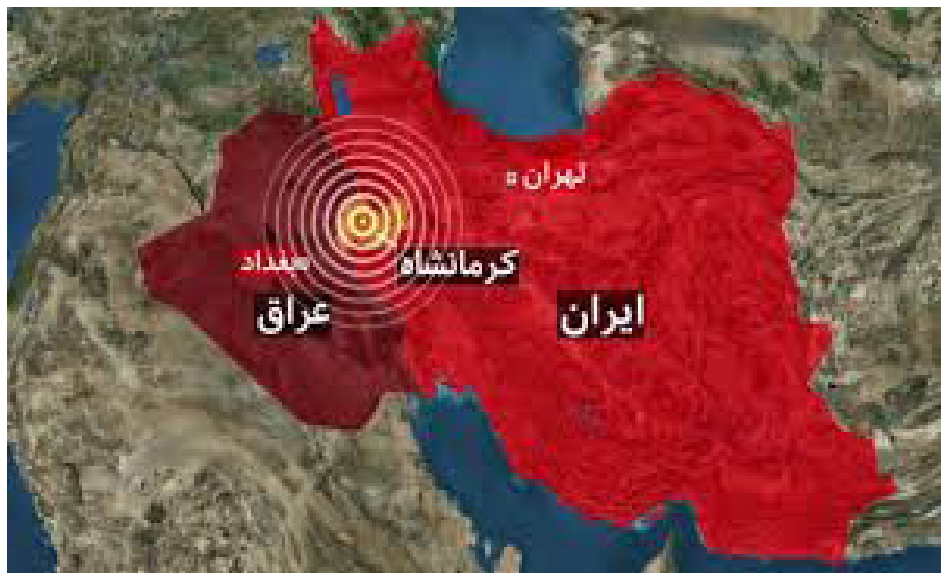

Figure 1. The epicenter of Kermanshah earthquake

Hilealth in
Emergencies and |D]isasters [Oluarterly

\section{Results}

Table 1 presents the demographic statistics of Kermanshah earthquake, separately for each city. According to Table 1, the lowest and the highest number of affected villages in the Kermanshah Province were in Sarpol-e Zahab (205 villages) and Qasr-e Shirin (29 villages), respectively. In addition, the highest and the lowest urban and rural populations were in Eslamabad-e Gharb (79541 in cities and 50584 in villages) and Salas-e Babajani (16359 in cities and 19435 in villages), respectively. The estimated population of Kermanshah Province at the time of earthquake was 370925; a total of 138564 individuals were affected by the earthquake. In addition, 113371 households lived in Kermanshah Province at the time of earthquake, out of them a total of 35726 households were affected by the earthquake, and 470 individuals were killed in the earthquake. Moreover, it is estimat- ed that out of 79360 houses in the Kermanshah Province at the time of earthquake, 34011 houses remained intact and 45349 houses were damaged.

Table 2 presents the results regarding the water supplies of the cities affected by Kermanshah earthquake, reported for each city. As shown in Table 2, the highest and the lowest number of households with access to tap water were in Sarpol-e Zahab (12548 households) and Qasr-e Shirin (1111 households), respectively. In addition, the highest and the lowest number of households with access to improved water sources were in Gilan-e Gharb (254 households) and Qasr-e Shirin (11 households), respectively.

The improved water sources in the areas affected by the earthquake included 51 low-risk water sources, 171 moderate-risk water sources, 2 high-risk water sources, and 0 very high-risk water sources. In addition, $5059 \mathrm{~m}^{3}$

Table 1. Demographic statistics of the cities affected by Kermanshah earthquake

\begin{tabular}{|c|c|c|c|c|c|c|c|c|}
\hline \multirow{2}{*}{ City } & \multicolumn{2}{|c|}{ Population } & \multicolumn{2}{|c|}{ Number of Households } & \multirow{2}{*}{$\begin{array}{l}\text { Number of } \\
\text { Villages }\end{array}$} & \multicolumn{3}{|c|}{$\begin{array}{c}\text { Number of Healthcare and Local } \\
\text { Health Centers }\end{array}$} \\
\hline & Urban & Rural & Urban & Rural & & \multicolumn{3}{|c|}{ Urban Centers and Bases } \\
\hline Sarpol-e Zahab & 37027 & 49897 & 14272 & 11397 & 205 & 8 & 7 & 49 \\
\hline Qasr-e Shirin & 18958 & 3954 & 4739 & 2164 & 29 & 3 & 1 & 7 \\
\hline Dalahoo & 17351 & 20614 & 3470 & 6795 & 139 & 4 & 2 & 36 \\
\hline $\begin{array}{l}\text { Eslamabad-e } \\
\text { Gharb }\end{array}$ & 79541 & 50584 & 15908 & 26559 & 159 & 12 & 5 & 58 \\
\hline Salas-e Babajani, & 16359 & 19435 & 3271 & 6686 & 147 & 2 & 3 & 33 \\
\hline Gilan-e Gharb & 27980 & 29225 & 5596 & 12514 & 181 & 3 & 4 & 42 \\
\hline Total & \multicolumn{2}{|c|}{370925} & 47256 & 66115 & 860 & 32 & 22 & 225 \\
\hline
\end{tabular}


Table 2. Water sources of the cities affected by Kermanshah earthquake

\begin{tabular}{|c|c|c|c|c|c|c|c|c|c|}
\hline \multirow[t]{2}{*}{ City } & \multirow[t]{2}{*}{$\begin{array}{l}\text { Number } \\
\text { of Villages }\end{array}$} & \multicolumn{2}{|c|}{$\begin{array}{c}\text { Number of } \\
\text { Water Sources }\end{array}$} & \multicolumn{2}{|c|}{ Type of Water Source } & \multicolumn{2}{|c|}{$\begin{array}{l}\text { Number of House- } \\
\text { Holds With Access to } \\
\text { Tap Water }\end{array}$} & \multicolumn{2}{|c|}{$\begin{array}{l}\text { Number of House- } \\
\text { Holds With Access } \\
\text { to Improved Water } \\
\text { Sources }\end{array}$} \\
\hline & & Urban & Rural & Urban & Rural & Village & Household & Village & Household \\
\hline $\begin{array}{l}\text { Sarpol-e } \\
\text { Zahab }\end{array}$ & 205 & 1 & 31 & Sarabgarm & Sarabgarm & 194 & 12548 & 11 & 172 \\
\hline Qasr-e Shirin & 29 & 1 & 2 & Sarabgarm & Sarabgarm & 25 & 1111 & 4 & 11 \\
\hline Dalahoo & 139 & 3 & 71 & Sarab Karand & Sarab Karand & 126 & 5021 & 13 & 145 \\
\hline $\begin{array}{l}\text { Eslamabad-e } \\
\text { Gharb }\end{array}$ & 159 & 19 & 44 & Water well & Water well & 153 & 12987 & 6 & 42 \\
\hline $\begin{array}{l}\text { Salas-e } \\
\text { Babajani, }\end{array}$ & 147 & 3 & 55 & $\begin{array}{l}\text { Spring and } 2 \\
\text { water wells }\end{array}$ & Spring & 123 & 4270 & 17 & 165 \\
\hline $\begin{array}{l}\text { Gilan-e } \\
\text { Gharb }\end{array}$ & 181 & 3 & 17 & $\begin{array}{l}\text { Spring and } \\
\text { Sarab }\end{array}$ & $\begin{array}{l}\text { Water supply } \\
\text { complex }\end{array}$ & 170 & 7761 & 11 & 254 \\
\hline Total & 860 & 30 & 220 & - & - & 791 & 43698 & 62 & 789 \\
\hline
\end{tabular}

water was chlorinated by the environmental health experts and 1805 households were under the coverage of methoxymethyl chloride.

Table 3 presents the results regarding the toilet conditions and waste disposal methods in the cities affected, separately reported for each city. As shown in Table 3, the highest and the lowest number of households with access to sanitary toilets were in Sarpol-e Zahab (11871 households) and Qasr-e Shirin (1078 households), respectively. In addition, the highest and the lowest number of households with access to sanitary waste disposal were in Sarpol-e Zahab (11758 households) and Qasr-e Shirin (1089 households), respectively.
Table 4 presents the results regarding the food supply and distribution centers and public places in the cities affected by Kermanshah earthquake. As shown in the Table 4, the lowest and the highest number of urban and rural schools were in Gilan-e Gharb (97 schools in cities and 183 schools in villages) and Qasr-e Shirin (21 schools in cities and 19 schools in villages), respectively. In addition, the lowest and the highest number of urban and rural food supply and distribution centers were in Gilan-e Gharb (1283 centers in cities and 403 in villages) and Qasr-e Shirin (241 centers in cities and 22 in villages), respectively.

Table 3. Toilet conditions and waste disposal methods in Kermanshah Province

\begin{tabular}{ccccccc}
\hline \multirow{2}{*}{ City } & \multicolumn{2}{c}{ Number of Toilets } & $\begin{array}{c}\text { Number of Households With Ac- } \\
\text { cess to Sanitary Toilets }\end{array}$ & $\begin{array}{c}\text { Number of Households With Ac- } \\
\text { cess to Sanitary Waste Disposal }\end{array}$ \\
\cline { 2 - 6 } & Urban & Rural & Village & Household & Village & Household \\
\hline Sarpol-e Zahab & 7136 & 205 & 185 & 11871 & 186 & 11758 \\
Qasr-e Shirin & 4760 & 1951 & 29 & 1078 & 29 & 1089 \\
Dalahoo & 3470 & 1050 & 102 & 4036 & 110 & 4136 \\
\hline Eslamabad-e Gharb & 15908 & 26559 & 144 & 11844 & 117 & 11674 \\
\hline Salas-e Babajani & 1309 & 441 & 98 & 3301 & 126 & 3832 \\
\hline Gilan-e Gharb & 5596 & 12514 & 160 & 7675 & 174 & 7830 \\
\hline Total & 38179 & 50776 & 718 & 39805 & 742 & 40319 \\
\hline
\end{tabular}


Table 4. Number of food supply and distribution centers and public places

\begin{tabular}{|c|c|c|c|c|c|c|}
\hline \multirow{2}{*}{ City } & \multicolumn{2}{|c|}{$\begin{array}{c}\text { Number of Food Supply and } \\
\text { Distribution Centers }\end{array}$} & \multicolumn{2}{|c|}{ Number of Schools } & \multicolumn{2}{|c|}{ Number of Mosques } \\
\hline & Urban & Rural & Urban & Rural & Urban & Rural \\
\hline Sarpol-e Zahab & 646 & 245 & 40 & 177 & 10 & 66 \\
\hline Qasr-e Shirin & 241 & 22 & 21 & 19 & 7 & 16 \\
\hline Dalahoo & 285 & 102 & 28 & 100 & 3 & 18 \\
\hline Eslamabad-e Gharb & 1283 & 403 & 97 & 161 & 14 & 49 \\
\hline Salas-e Babajani & 338 & 131 & 21 & 125 & 10 & 80 \\
\hline Gilan-e Gharb & 456 & 307 & 97 & 183 & 5 & 29 \\
\hline Total & 3349 & 1210 & 304 & 765 & 49 & 258 \\
\hline
\end{tabular}

Table 5 presents the results regarding the environmental health condition of the cities affected by Kermanshah earthquake, in three aspects: environmental health of public places, food safety, and solid waste management. Table 6 presents the urgent equipment announced by the environmental health group of the Vice Chancellor for Clinical Affairs at Kermanshah University of Medical Sciences, following the earthquake.

\section{Discussion}

The present study was conducted by a team of researchers and experts at Kermanshah city health department in autumn 2017, aimed at examining the health condition of the cities affected by Kermanshah earthquake and also analyzing the activities in this regard. The environmental health team with the cooperation of the other crisis management teams took important steps to improve the health condition of the areas affected by Kermanshah earthquake. Some of the steps included checking drinking water storage tanks, chloride testing and water chlorination, monitoring the quality of distributed foods, building sanitary bathrooms and toilets, monitoring proper waste and wastewater management, and also providing useful and practical instructions. These activities were successfully completed at all stages, and were effective in controlling the spread of diseases and helping recovery of the affected areas a normal state.

One of the strengths of the works conducted by the environmental health team in the affected areas was helping in better management of drinking water and improving water quality, also assisting in better dis-

Table 5. Environmental health condition of the cities affected by Kermanshah earthquake

\begin{tabular}{|c|c|c|c|c|}
\hline & Parameter & Intact & Damaged & Total \\
\hline \multirow{4}{*}{$\begin{array}{l}\text { Health condition of food } \\
\text { supply and distribution cen- } \\
\text { ters and public places }\end{array}$} & Number of schools and learning centers & 642 & 427 & 1069 \\
\hline & Number of mosques and holy places & 215 & 92 & 307 \\
\hline & Number of healthcare centers & 195 & 84 & 279 \\
\hline & Number of hospitals & 2 & 2 & 4 \\
\hline \multirow{3}{*}{ Food health } & Number of food supply and distribution centers & 3199 & 1360 & 4559 \\
\hline & & & & \\
\hline & Number of food stores and cool stores & 5 & - & 5 \\
\hline \multirow{2}{*}{ Solid waste management } & Number of waste disposal sites & 8 & 2 & 10 \\
\hline & Number of temporary waste transfer stations & 8 & 2 & 10 \\
\hline
\end{tabular}


Table 6. The equipment needed for monitoring and controlling water and wastewater in the areas affected by Kermanshah earthquake

\begin{tabular}{|c|c|}
\hline Materials/Equipment & Number of People Affected By The Earthquake: 138000 \\
\hline $\begin{array}{l}\text { Water sampling equipment (Sterile bottle, gauze pad, cotton and } \\
\text { matches, sample labels) }\end{array}$ & 1000 series \\
\hline Chlorine and $\mathrm{pH}$ test kits & 100 units \\
\hline Sample carrying cases & 100 units \\
\hline Portable turbidity test kits & 100 units \\
\hline E. coli microbial water test kits & 100 units \\
\hline Portable computer with modem and the necessary software & 20 units \\
\hline Paper, pen, and pencil & 100 series \\
\hline Mobile laboratory & 1 unit \\
\hline Water purification tablets & 100000 tablets \\
\hline Portable water purification machines & 100 units \\
\hline
\end{tabular}

Portable storage containers in different sizes: $20-\mathrm{L}, 100-\mathrm{L}$, and 1000-L

TF-35 thermal foggers

Manual sprayers with flat fan nozzles

Fog machines

Wettable powder insecticides (Solfac, Lambda-Cyhalothrin, Ficam)

Liquid insecticides (symporter, k-Othrine)

Rodenticides

Disinfectants

Hand sanitizers (gel or liquid) for the health teams

Personal protection equipment for environmental vector control

Momentary air quality monitor

Sampling kit

Sterile jars

Cold boxes

Solid ice

Plastic bags in large, medium, and small sizes

Infrared thermometers

Rapid test kit with reagents

lodine test kits

Sample labels
20-L: 50000 units, 100-L: 10000 units

10 units

10 units

5 units

$350 \mathrm{~kg}$

$700 \mathrm{~L}$

$100 \mathrm{~kg}$

$28000 \mathrm{~L}$

$200 L$

50 series

2 machines

100 units

500 units

100 units

1000 units

600 packs

100 units

100 series

100 kits

100 packs

Emergencies and (D) isasters [Oluarterly 
tribution of services by the active groups in the environmental health domain. From the moment the earthquake occurred, the environmental health experts started monitoring the equality of drinking water, water chlorination, and microbial sampling.

In Aslehashemi et al. study, the major aspects of environmental health, such as waste and wastewater management, providing healthy drinking water, disinfestation, and proper monitoring of food supply and distribution centers were examined [15]. Our examination of the activities in the areas affected by Kermanshah earthquake showed that all the aforementioned parameters were adequately considered. In addition, the study results indicated that in the affected areas, there were 250 urban and rural water supplies, 43698 households with access to tap water, and 789 households with access to improved water sources.

Along with the populations of the cities and the staff and operating workers, a total of 41 environmental health workers worked in the areas affected by the earthquake. This number is consistent with WHO suggestion, i.e. 2 staff workers and 8 to 15 operating workers per 5000 to 100000 people affected by the earthquake [16] However, in the study by Akbari et al. on Bam earthquake, there was 1 environmental health worker per 50000 people affected by the earthquake [17]. We also assessed the adequacy of human resources, appropriate organization of environmental health forces in the rural areas, and recruiting forces from Kermanshah Province due to their familiarity with the region's geographical, social, and cultural aspects, in order to increase the effectiveness of the environmental health services provided in the areas affected by the earthquake.

The number of households with access to sanitary toilets in the affected areas was 39805 that is consistent with the finding of Fatemi et al. [18]. However, the toilets had been installed without paying proper attention to the minimum standards, such as selecting a suitable place, not too far from the survivors so that they could conveniently access the toilets, sound substructure, and adequate water piping. Formation of wastewater ponds in some areas acted as an environmental risk factor in attracting insects and rodents, and increased the risk of vector transmission and possible epidemics [19]. However, regular disinfecting and spraying by the environmental health workers reduced this risk factor to a considerable extent.

\section{Conclusion}

In conclusion, the results indicated that the steps taken by the environmental health experts were sufficiently effective in meeting the needs of affected areas by Kermanshah earthquake in terms of providing healthy drinking water, proper waste and wastewater management, proper food supply and distribution, and so on. This experience can be a good model for meeting the needs of the survivors from future natural disasters and crises.

\section{Ethical Considerations}

\section{Compliance with ethical guidelines}

The present study was conducted by paying special attention to the privacy of personal information and all the ethical codes in this regard.

\section{Funding}

This research did not receive any specific grant from funding agencies in the public, commercial, or not-forprofit sectors.

\section{Authors contributions}

All the authors have read and approved the manuscript.

\section{Conflict of interest}

The authors declared no conflict of interest.

\section{Acknowledgements}

The authors wish to sincerely thank the environmental health experts and the Vice Chancellor for Clinical Affairs of Kermanshah University of Medical Sciences who vigorously helped us in gathering the study data.

\section{References}

[1] Dargahi A, Farrokhi M, Poursadeghiyan M, Ahagh MMH, Karami A. Evaluation of functional preparedness and non structural safety of different health units of Kermanshah University of Medical Sciences in coping with natural disasters. Health in Emergencies \& Disasters Quarterly. 2017; 2(4):201-6.

[2] Nivolianitiou Z, Synodinou B. Towards emergency management of natural disasters and critical accidents: The Greek experience. Journal of Enviromental. 2011; 92(10):2657-65. [DOI:10.1016/j.jenvman.2011.06.003] 
[3] Dargahi A, Bagheri S, Poursadeghiyan M, Ahagh MMH, Farrokhi M. Knowledge and attitudes of students in Khalkhal medical sciences faculty on health actions in emergencies. Health in Emergencies \& Disasters Quarterly. 2017; 3(1):51-6.

[4] Khankeh HR, Mohammadi R, Ahmadi F. Health care services at time of natural disasters: A qualitative study. Iran Journal of Nursing. 2007; 20(51):85-96.

[5] Brown C, Milke M, Seville E. Disaster waste management: A review article. Waste Management. 2011; 31(6):1085-98. [DOI:10.1016/j.wasman.2011.01.027] [PMID]

[6] Miri A, Hami M, Dargahi A, Poursadeghiyan M, Farrokhi M, Ivanbagha R, et al . Study on the awareness of the students of Azad University of Medical Sciences about nutrition and food storing stuff during crisis. Health in Emergencies and Disasters Quarterly. 2018; 3(2):91-6.

[7] Myers DG, Wee DF. Disaster mental health services: A primer for practitioners. New York: Psychology Press; 2005.

[8] Rafee N, Karbassi AR, Nouri J, Safari E, Mehrdadi M. Strategic management of municipal debris aftermath of an earthquake. International Journal of Environmental Research. 2008; 2(2):205-14

[9] Heidarzadeh N, Ramezani Khoojin A. [Steps and measures of construction and demolition waste management in natural disasters (Persian)]. Journal of Human and Environment. 2015; 1(32):57-71.

[10] Gharib F, Kosha A, Beiknoori MF, Rouhani Majd S. [A survey of earthquake-affected region and controlling actions to communicable and non-communicable diseases in Azerbaijan earthquake, 2012 (Persian)]. Depiction of Health. 2013; 4(3):32-41.

[11] Farrokhi M, Dolatabadi ZA, Pakjouei S, Pouyesh V. [Review paper: Approaches to post-disaster environmental recovery (Persian)]. Health in Emergencies and Disasters. 2016; 1(2):65-70.

[12] Ardalan A, Rajaei MH, Masoumi G, Azin A, Zonoobi V, Sarvar M, et al. 2012-2025 Roadmap of I.R.Iran's disaster health management. PLOS Currents. 2012; 4:e4f93005fbcb34 [DOI:10.1371/4f93005fbcb34]

[13] Seyedin H, Abbasi Dolatabadi Z, Rajabifard F. Emergency nurses' requirements for disaster preparedness. Trauma Monthly. 2015; 20(4):e29033. [DOI:10.5812/traumamon.29033] [PMID] [PMCID]

[14] Ardalan A, Moradian M.J, Gouya M, Nadafi K, Motlagh M, Abdollahi Z, et al. [National public health disaster and emergency operations plan (Persian)]. Tehran: Ministry of Health and Medical Education; 2011.

[15] Asl Hashemi A, Dianat I, Taghipour H. [Evaluation of environmental health experts' knowledge regarding health issues in natural disasters (Persian)]. Quarterly Scientific Journal of Rescue \& Relief. 2012; 4(3):16-22.

[16] Sphere Project. Humanitarian charter and minimum standards in disaster response. Geneva: The Sphere Project; 2011.

[17] Akbari ME, Farshad AA, Asadi-Lari M. [The devastation of Bam: An overview of health issues 1 month after the earthquake (Persian)]. Public Health. 2004; 118(6):403-8. [DOI:10.1016/j.puhe.2004.05.010] [PMID]
[18] Fatemi F, Mohammadi H, Ardalan A, Naddafi K. [Assessment of environmental health in the 2012 East Azerbaijan earthquake (Persian)]. Iranian Journal of Health and Environment. 2013; 6(2):177-86.

[19] Ishii A. Wastewater and solid waste management- Abbottabad conservation strategy: Sector paper. Pakistan: Pakistan Environmental Protection Agency; 2002. 